\title{
Atmospheric occurrence, transport and deposition of polychlorinated biphenyls and hexachlorobenzene in the Mediterranean and Black seas
}

\author{
N. Berrojalbiz ${ }^{1}$, J. Castro-Jiménez ${ }^{1}$, G. Mariani ${ }^{2}$, J. Wollgast ${ }^{2}$, G. Hanke ${ }^{2}$, and J. Dachs ${ }^{1}$ \\ ${ }^{1}$ Department of Environmental Chemistry. Institute of Environmental Assessment and Water Research (IDAEA - CSIC), \\ Barcelona, Catalunya, Spain \\ ${ }^{2}$ European Commission - DG Joint Research Centre, Institute for Environment and Sustainability, Ispra, Italy
}

Correspondence to: J. Dachs (jordi.dachs@idaea.csic.es)

Received: 27 February 2014 - Published in Atmos. Chem. Phys. Discuss.: 14 April 2014

Revised: 4 July 2014 - Accepted: 21 July 2014 - Published: 1 September 2014

\begin{abstract}
The Mediterranean and Black seas are unique marine environments subject to important anthropogenic pressures due to direct and indirect loads of atmospheric inputs of organochlorine compounds (OCls) from primary and secondary sources. Here we report the results obtained during two east-west sampling cruises in June 2006 and May 2007 from Barcelona to Istanbul and Alexandria, respectively, where gas-phase and aerosol-phase samples were collected. Both matrices were analyzed for 41 polychlorinated biphenyls (PCBs), including dioxin-like congeners, and hexachlorobenzene (HCB). The values reported in this study for gas-phase $\mathrm{HCB}$ and $\sum_{41} \mathrm{PCB}$ limit of detection (LOD) to $418.3 \mathrm{pg} \mathrm{m}^{-3}$ and from 81.99 to $931.6 \mathrm{pg} \mathrm{m}^{-3}$ respectively) are in the same range of those reported in former studies, possibly suggesting a limited decline in their atmospheric concentrations during the last decade for the Mediterranean region due to land-based $\mathrm{OCl}$ sources. There is a clear influence of the direction of the air mass on the atmospheric concentrations of PCBs, with higher concentrations when the air mass was from southern Europe, and the lowest concentrations for air masses coming from the SW Mediterranean and Atlantic Ocean. PCBs and HCB are close to air-water equilibrium for most sampling periods, thus resulting in low atmospheric deposition fluxes at open sea. This is consistent with the oligotrophic character of the Mediterranean Sea with a small influence of the biological pump capturing atmospheric PCBs. Therefore, degradation of gas-phase PCBs by $\mathrm{OH}$ radicals is estimated to be the main loss process of atmospheric PCBs during their transport over the Mediterranean Sea. Conversely, atmospheric residence times of $\mathrm{HCB}$
\end{abstract}

are predicted to be very long due to a lack of atmospheric degradation and low depositional fluxes due to concentrations at air-water equilibrium.

\section{Introduction}

Among the thousands of anthropogenic compounds emitted to the atmosphere, chemicals embraced within the group of the persistent organic pollutants (POPs) have obtained relevant attention due to their persistence, bioaccumulation potential and proved toxic effects (United Nations, 2014). Organochlorine compounds (OCls), such as polychlorinated biphenyls (PCBs) and hexachlorobenzene (HCB), are among the POPs that have been studied extensively due to their ubiquitous occurrence, and potential for long-range atmospheric transport, being a paradigm of globally distributed pollutants. In addition, the wide range of physical-chemical properties of PCBs makes them useful as a surrogate of the behavior of other semi-volatile and hydrophobic POPs, including those whose presence in the environment is relatively recent and thus not yet properly quantified at regional and global scales. Although international regulations such as the Stockholm Convention have banned or restricted the global emissions of many OCls, the consequent expected decline trend in their atmospheric concentrations has not been as fast as predicted, and has varied upon location/region, time period and specific compounds (Hung et al., 2005). In fact, current atmospheric levels of these chemicals in the atmosphere may 
be explained as a result of the interplay of different factors (Nizzetto et al., 2010a, b): (i) primary sources as a direct result of the intentional production and usage or accidental releases of materials containing OCls; (ii) secondary emission sources as the consequence of re-volatilization of previously released OCls from environmental reservoirs, such as sea-air or soil-air diffusive exchange (Brevik et al., 2002); and (iii) the removal processes which are also particular for each compound (Wania and Daly, 2002; Dachs et al., 2002). Nevertheless, there are still large uncertainties regarding the different factors controlling the atmospheric occurrence and deposition of OCls, especially when referring to the marine atmospheric environment due to the scarcity of the available data and the difficulties associated with the generation of reliable new measurements.

The persistence and subsequent long half-lives in air make OCls prone to long-range atmospheric transport before their removal by deposition or reaction with $\mathrm{OH}$ radicals (Bidleman, 1999; Anderson and Hites, 1996; Mandalakis et al., 2003; Jurado and Dachs, 2008). The distribution of the compounds in the atmosphere between the aerosol and gas phases will determine to a great extent the relative importance of these loss processes. The inputs of OCls to the open sea come from the combination of three depositional processes: dry deposition driven by particle settling (Jurado et. al., 2004), wet deposition through scavenging of OCls by rain or snow (Jurado et al., 2005), and especially diffusive airwater exchange (Jaward et al., 2004; Jurado et al., 2004). Atmospheric deposition supports $\mathrm{OCl}$ accumulation in biota at open sea, where their harmful effects could threaten the marine ecosystem and humans through different exposure routes. In consequence, it is important to gain knowledge of the occurrence and deposition of POPs in the marine background atmosphere in order to quantify their inputs, dynamics, and impacts in the oceanic environment.

The Mediterranean region is surrounded by Europe and Africa where highly developed industrial countries in the north stand in contrast to the developing countries in the southern basin. Historically, the Mediterranean and Black seas have been recipients of significant anthropogenic pressures of direct and indirect loads of OCls from intensive industrial and agricultural activities (Tolosa et al., 1997; Turley et al., 1999). However, the atmospheric measures of $\mathrm{OCl}$ concentrations in the Mediterranean Sea region are scarce. For the open sea these have been focused on polychlorinated dibenzo-dioxins and furans (Castro-Jiménez et al., 2010), while for other $\mathrm{OCl}$ the previous studies have only covered local coastal sites (Mandalakis and Stephanou, 2002; GarcíaFlor et al., 2009; Castro-Jiménez et al., 2010). Therefore, the main objectives of this work are (i) to provide a large data set of PCB and HCB concentrations in the open Mediterranean and SW Black Sea atmosphere; (ii) to quantify the atmospheric deposition of PCBs and HCB to the Mediterranean Sea; and (iii) evaluate the factors and processes affecting the

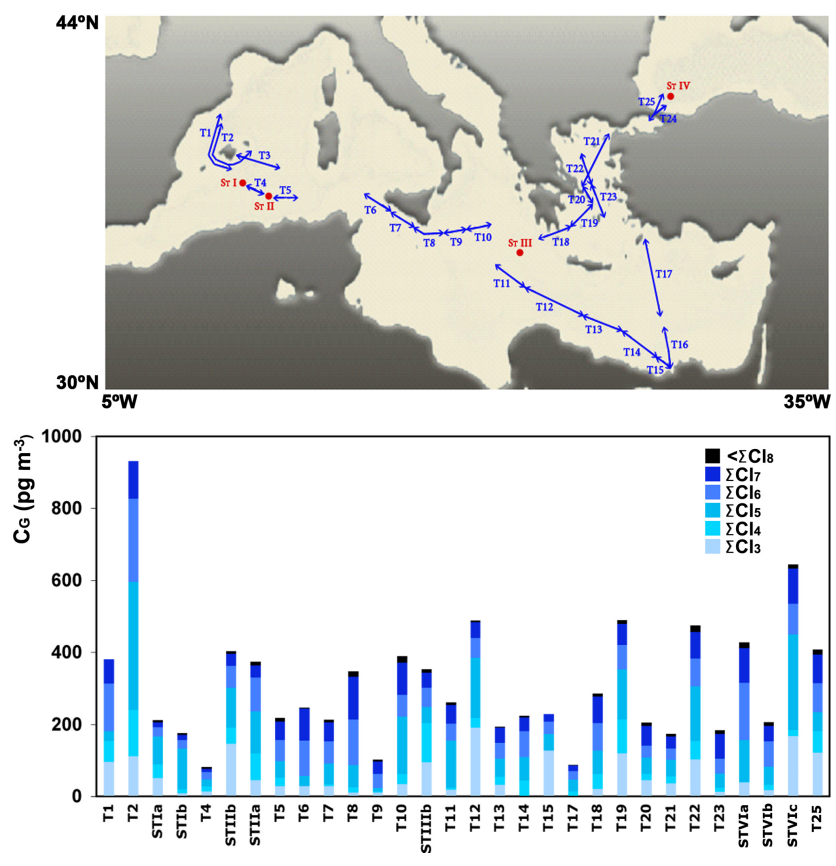

Figure 1. Location of the atmospheric samples and spatial distribution of gas-phase concentrations of PCBs $\left(\mathrm{pg} \mathrm{m}^{-3}\right)$.

occurrence and deposition of PCBs and HCB in the Mediterranean marine atmosphere.

\section{Materials and methods}

\subsection{Sample collection}

Air samples were collected on board the R/V Garcia del Cid during the two THRESHOLDS sampling cruises carried out in June 2006 and May 2007. For both cruises, Barcelona was the initial and final port, with Istanbul and Alexandria being the intermediate stops, respectively. Transects covered an extensive area within a year of difference allowing for a good spatial coverage of the different Mediterranean basins (Fig. 1).

The air samples for $\mathrm{OCl}$ analysis were taken using a highvolume air sampler (MCV, Barcelona, Spain) operating at a flow rate of $40 \mathrm{~m}^{3} \mathrm{~h}^{-1}$ located above the bridge (at 6$7 \mathrm{~m}$ a.s.1.). On average, samples were collected within $12 \mathrm{~h}$, and the mean sampled air volume was of $500 \mathrm{~m}^{3}$, ranging from 230 to $950 \mathrm{~m}^{3}$. In addition, a second high-volume sampler was operated simultaneously to collect samples with larger sampled volumes allowing for the determination of mono-ortho dioxin-like PCB (300-1600 $\mathrm{m}^{3}$ ) (see Supplement A). Both high-volume air samplers were controlled by a weather station to avoid smokestack and minimize interference from any potential ship contamination. The air was drawn through a precombusted quartz filter (QM-A; Whatman, $8 \times 10$ inches) to collect aerosol-bound compounds and 


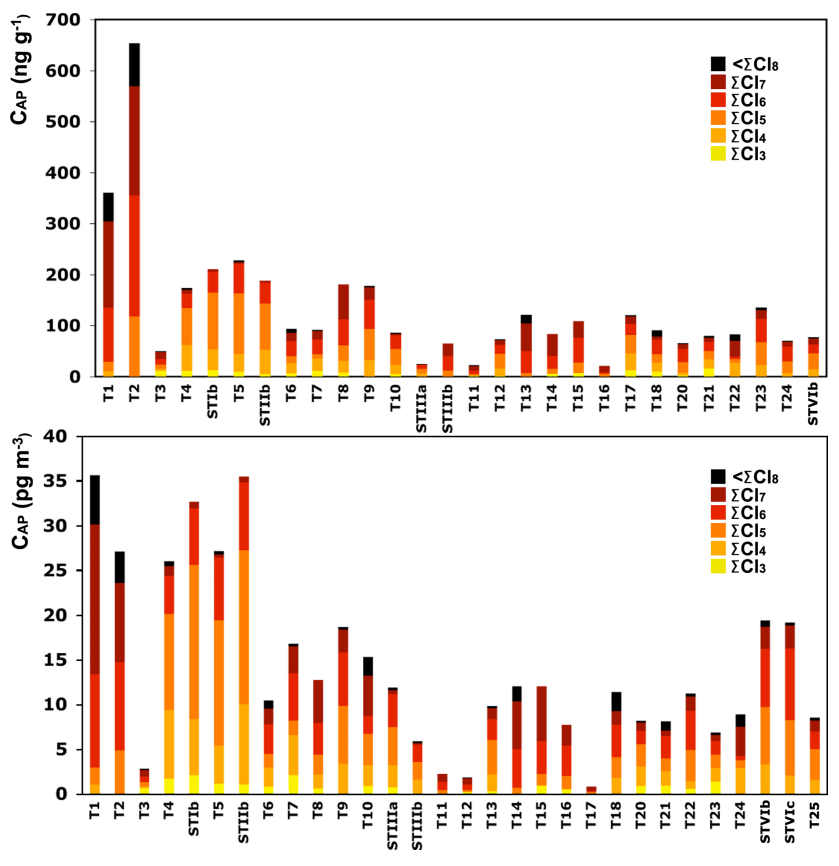

Figure 2. Spatial distribution of PCBs concentrations in the aerosol phase $\left(\mathrm{pg} \mathrm{m}^{-3}\right.$ and $\left.\mathrm{pg} \mathrm{m}^{-3}\right)$.

then circulated through a polyurethane foam (PUF) to collect chemicals present in the gas phase. All samples were stored in freezers at $-20^{\circ} \mathrm{C}$ until analysis. Prior to sampling, PUFs were rinsed with acetone: hexane $(1: 1, v / v)$, then Soxhlet extracted for $24 \mathrm{~h}$ and dried into a vacuum desiccator.

Throughout the campaign, meteorological parameters, including temperature, wind speed and wind direction, were measured using the meteorological station located on the deck of the ship. In order to examine the origin of the air masses for each sampling period and region, air mass backtrajectories were calculated using the HYSPLIT model of NOAA, and $48 \mathrm{~h}$ back-trajectories were determined every $6 \mathrm{~h}$ for 15 and $100 \mathrm{~m}$ of altitude at the start and end locations of each sampling transect (see Supplement B).

\subsection{Chemical analysis}

Prior to extraction, all samples were spiked with PCB 65 and PCB 200 which were used as surrogate standards. PUFs were Soxhlet extracted with acetone : hexane $(1: 1, v / v)$ for $24 \mathrm{~h}$. The extracts were rotary evaporated to $1 \mathrm{~mL}$ and purified on a $3 \%$ Milli-Q grade water deactivated alumina column ( $3 \mathrm{~g})$ with a top layer of anhydrous sodium sulfate. Each column was eluted with $5 \mathrm{~mL}$ hexane. The extract was concentrated to $0.5 \mathrm{~mL}$ by vacuum rotary evaporation, transferred to a $1.7 \mathrm{~mL}$ amber vial with isooctane and evaporated to $150 \mu \mathrm{L}$ under a gentle nitrogen stream. At this step, $5 \mathrm{ng}$ of PCB 30 and PCB 142, used as internal standards, were added to the extract. QM-A filters were freeze-dried, weighed and Soxhlet extracted with dichloromethane : methanol $(2: 1, v / v)$ for
$24 \mathrm{~h}$. The extracts were rotary evaporated to $1 \mathrm{~mL}$, solventexchanged to hexane and purified following the same protocol as described for gas-phase samples.

All samples were analyzed for 41 PCB congeners and HCB by gas chromatography coupled to an electron capture detector operating with splitless injection mode. The separation was achieved with a $60 \mathrm{~m} \times 0.25 \mathrm{~mm}$ i.d. $\times 0.25 \mu \mathrm{m}$ capillary column. The oven temperature was programmed from $90^{\circ} \mathrm{C}$ (holding time $1 \mathrm{~min}$ ) to $190^{\circ} \mathrm{C}$ at $2^{\circ} \mathrm{C} \mathrm{min}^{-1}$, and finally $310^{\circ} \mathrm{C}$ at $3{ }^{\circ} \mathrm{C} \min ^{-1}$ keeping the final temperature for $18 \mathrm{~min}$. Compounds were quantified by the internal standard procedure (see Supplement C for instrumental detection limits).

In addition, a selected group of samples with higher sampled volumes were also used to quantify eight mono-ortho PCB congeners (PCB 105, PCB 114, PCB 118, PCB 123, PCB 156, PCB 157, PCB 167 and PCB 189). The analysis of this group of samples containing 18 gas- and aerosol-phase samples (see Supplement A) was performed by isotope dilution high-resolution gas chromatography coupled to a highresolution mass spectrometer (HRGC-HRMS) on the basis of EPA 1668 method (Castro-Jiménez et al., 2010).

The quantification of the concentration of aerosol was performed by gravimetry. The content of the organic and elemental fraction of aerosols was performed by using the thermal optical transmittance in a sunset laboratory carbon analyzer using the NIOSH temperature protocol (Birch and Cary 1996).

\subsection{Quality assurance and quality control}

The analytical procedure was validated by determining the recovery rates of the surrogates for each sample, which had medians of 74 and $64 \%$ for the gas and aerosol phase, respectively (see Supplement B). Moreover, a total of 10 blank samples ( 5 for PUF, 5 for QM-A filters) were collected to test the background contamination during the sample preparation, transportation, treatment and analysis. These blanks were processed in parallel to the samples (see Supplement C). The potential breakthrough of PCBs during gas-phase sampling was evaluated by analyzing a second PUF for three sampling events using the second high-volume air samplers that sampled the largest air volumes needed for dl-PCBs. The results show that the second PUF contained less than $3 \%$ of the amount of dl-PCBs than the first PUF (see Supplement C).

\subsection{Estimation of the atmospheric deposition of PCBs and HCBs}

The dry deposition fluxes $\left(F_{\mathrm{DD}}, \mathrm{ng} \mathrm{m}^{-2} \mathrm{~d}^{-1}\right)$ were calculated as

$F_{\mathrm{DD}}=v_{\mathrm{D}} C_{\mathrm{AP}}$,

where $C_{\mathrm{AP}}$ is the volumetric concentration of PCBs or HCB in the aerosol phase $\left(\mathrm{ng} \mathrm{m}^{-3}\right)$ and $v_{\mathrm{D}}$ is the deposition 
velocity of particles $\left(\mathrm{m} \mathrm{d}^{-1}\right)$. Due to the lack of field measurements of $v_{\mathrm{D}}$ over the Mediterranean Sea and during the THRESHOLDS cruises reported here, we assume a value of $0.2 \mathrm{~cm} \mathrm{~s}^{-1}$ as representative of marine aerosol deposition velocity. This value is slightly above the average value measured in the Atlantic Ocean (Del Vento and Dachs, 2007a), but it is slightly lower than those measured at a coastal western Mediterranean station (Del Vento and Dachs, 2007b) and within the range of what was calculated for the coastal eastern Mediterranean (Mandalakis et al., 2005).

The diffusive air-water exchange fluxes $\left(F_{\mathrm{AW}}\right.$, $n g \mathrm{~m}^{-2} \mathrm{~d}^{-1}$ ) were estimated by

$$
F_{\mathrm{AW}}=1000 k_{\mathrm{AW}}\left[\frac{C_{\mathrm{G}}}{H^{\prime}}-C_{\mathrm{W}}\right] \text {, }
$$

where $k_{\mathrm{AW}}$ is the air-water mass transfer coefficient $\left(\mathrm{m} \mathrm{d}^{-1}\right)$, $C_{\mathrm{G}}\left(\mathrm{pg} \mathrm{m}^{-3}\right)$ and $C_{\mathrm{W}}\left(\mathrm{pg} \mathrm{m}^{-3}\right)$ are the $\mathrm{OCl}$ concentration in the gas and dissolved phases, respectively, and $H^{\prime}$ is the temperature- and salinity-corrected dimensionless Henry's law constant. The correction for salinity was done assuming a Setschenow constant of 0.3 (Swarzenback et al., 2003). $H$ values were taken from Harner and Bidleman (1996), Bamford et al. (2002), Li et al. (2003) and Shen and Wania (2005). $C_{\mathrm{W}}$ were measured simultaneously to the atmospheric concentrations and are discussed elsewhere (Berrojalbiz et al., 2011). For determining both diffusive air-water exchange fluxes and air-water fugacity ratios (see below), $C_{\mathrm{W}}$ was corrected by the dissolved organic carbon as reported elsewhere (García-Flor et al., 2005). Details on estimation methods for $k_{\mathrm{AW}}$ are explained elsewhere (Jurado et al., 2004). The nonlinear influence of wind speed has been taken into account by correcting $k_{\mathrm{WA}}$ considering a Weibull distribution of wind speeds (Simó and Dachs, 2002).

The fugacity approach has been used to further evaluate the significance of the direction of the diffusive air-water exchange $\left(f_{\mathrm{G}} / f_{\mathrm{W}}\right)$ and estimated by

$$
\frac{f_{\mathrm{G}}}{f_{\mathrm{W}}}=\frac{C_{\mathrm{G}}}{C_{\mathrm{W}} H^{\prime}} \text {. }
$$

The accuracy of the fugacity ratios is a strong function of the uncertainty of the measurements of $C_{\mathrm{G}}, C_{\mathrm{W}}$ and $H^{\prime}$. Most of the uncertainty in the fugacity ratios comes from the estimations of $H$ values (Bruhn et al., 2003) although there is also a small part coming from the intrinsic errors associated with the measurements of organic chemicals at low concentrations. Therefore, due to the uncertainly in $H^{\prime}$ values, when $f_{\mathrm{G}} / f_{\mathrm{W}}$ ranges from 0.3 to 3 , gas and dissolved phases can be assumed to be close to equilibrium; when $f_{\mathrm{G}} / f_{\mathrm{W}}>3$ there is a net absorption; and when $f_{\mathrm{G}} / f_{\mathrm{W}}<0.3$ there is a net volatilization.

\subsection{Principal component analysis of the data set}

Principal component analysis (PCA) was applied to the detect relationships among the different quantified variables.
Gas- and aerosol-phase samples were analyzed separately, including as variables in both matrices the sum of the concentrations of PCBs with the same amount of Cls (i.e., sum of tri- to heptachlorinated biphenyls), temperature and total suspended particles (TSPs) of each sample. PCA was performed on normalized (subtraction of mean and division by standard deviation) data using statistical software (SPSS 13.0).

\section{Results and discussion}

\subsection{Atmospheric occurrence of PCBs and HCB}

A summary of atmospheric concentrations in the gas $\left(C_{\mathrm{G}}\right.$, $N=34)$ and aerosol phases $\left(C_{\mathrm{AP}}, N=30\right)$ for $\mathrm{HCB}$ and individual PCBs is given in Table 1 (complete data set in Supplement D). The atmospheric concentrations of the eight dioxin-like PCB congeners are summarized in Table 3 for the gas $\left(C_{\mathrm{G}}^{*}, N=18\right)$ and aerosol phase $\left(C_{\mathrm{AP}}^{*}=18\right)$ (see Supplement D for complete data set). The sum of the measured $41 \mathrm{PCB}$ congeners $\left(\sum_{41} \mathrm{PCB}\right)$ ranged from 82.0 to $931.6 \mathrm{pg} \mathrm{m}^{-3}$, with a mean value of $297.3 \mathrm{pg} \mathrm{m}^{-3}$ for the gas-phase in the Mediterranean Sea atmosphere. Likewise, for the samples collected in the SW Black Sea, the $\sum_{41}$ PCB gas-phase concentration ranged from $206.2 \mathrm{pg} \mathrm{m}^{-3}$ to $644.2 \mathrm{pg} \mathrm{m}^{-3}$, with a mean concentration of $421.6 \mathrm{pg} \mathrm{m}^{-3}$. The highest $C_{\mathrm{G}}$ for the $\sum_{41} \mathrm{PCB}$ corresponded to the sample taken between Barcelona and Mallorca in 2007 (T2) followed by the sample taken in the Black Sea in 2006 (STIVc). The lowest $\sum_{41} \mathrm{PCB}$ concentrations were measured in transects from diverse locations in the open Mediterranean Sea (T4, T9 and T17). There was not a significant $(p<0.05)$ east-west trend in $\sum_{41}$ PCB gas-phase concentrations for the Mediterranean Sea, and there were no statistically significant differences between those samples taken in 2006 and 2007, nor between the Mediterranean and Black seas. The lack of significant differences between sub-basins and years points to other factors driving the observed variability in concentrations (see Sect. 3.3).

In order to compare PCB levels measured in this study with those reported in former works, the seven ICES PCB congeners $(28,52,118,101,153,138$, and 180) were selected (Table 2). $\sum_{\text {7ICES }}$ PCBs ranged from 27 to $259.4 \mathrm{pg} \mathrm{m}^{-3}$ in the Mediterranean Sea's gas phase, and from 98.70 to $166.15 \mathrm{pg} \mathrm{m}^{-3}$ in the Black Sea, with mean values of 88.1 and $136.9 \mathrm{pg} \mathrm{m}^{-3}$, respectively. On average, $\sum_{\text {7ICES }}$ PCBs account for $34 \%$ of $\sum_{41}$ PCB in both regions. The $\sum_{7 I C E S} \mathrm{PCB}$ gas-phase concentrations are in agreement with previous measurements made in northwestern Mediterranean Sea in 2002-2003 (García-Flor et al., 2009) and in the eastern Mediterranean Sea in 1999-2001 (Mandalakis and Stephanou, 2002). The $\sum_{41}$ PCB concentrations reported in this study are also in the same range of what was found by Iwata and coworkers in the Mediterranean Sea (sum of 40 congeners) (Iwata et al., 1993). This comparison suggests a 
Table 1. Summary of the PCB and HCB concentrations in the Mediterranean atmosphere.

\begin{tabular}{|c|c|c|c|c|c|c|c|c|}
\hline \multirow[b]{3}{*}{ Compound } & \multicolumn{4}{|c|}{ Gas phase $\left(\mathrm{pg} \mathrm{L}^{-1}\right)$} & \multicolumn{4}{|c|}{ Aerosol samples $\left(\mathrm{ng} \mathrm{g}^{-1}\right)$} \\
\hline & \multicolumn{2}{|c|}{ Mediterranean Sea $(N=30)$} & \multicolumn{2}{|c|}{ Black Sea and Sea of Marmara $(N=4)$} & \multicolumn{2}{|c|}{ Mediterranean Sea $(N=24)$} & \multicolumn{2}{|c|}{ Black Sea and Sea of Marmara $(N=4)$} \\
\hline & Median (Mean) & Range & Median (Mean) & Range & Median (Mean) & Range & Median (Mean) & Range \\
\hline $\mathrm{HCB}$ & $28.1(59.2)$ & (nd-418.3) & $42.0(49.5)$ & $(13.7-100.2)$ & $0.8(1.2)$ & (nd-6.7) & nd (1.7) & (nd-6.7) \\
\hline PCB 17 & $4.0(7.2)$ & (nd-29.4) & $10.3(22.7)$ & $(0.1-70.1)$ & nd $(0.6)$ & (nd-8.4) & nd & nd \\
\hline РCB 18 & $9.6(21.6)$ & (nd-170.3) & $11.9(16.9)$ & (nd-43.9) & nd $(0.6)$ & (nd-6.0) & nd & nd \\
\hline PCB 28 & $3.1(9.9)$ & (nd-72.8) & $18.4(24.2)$ & $(6.0-54.0)$ & $2.3(2.5)$ & (nd-9.0) & nd & nd \\
\hline PCB 31 & $\mathrm{nq}$ & $\mathrm{nq}$ & $\mathrm{nq}$ & $\mathrm{nq}$ & $1.1(2.0)$ & (nd-9.2) & nd & nd \\
\hline РCB 33 & $10.7(16.8)$ & (nd-52.1) & $5.6(22.9)$ & (nd-80.4) & nd $(0.4)$ & (nd-4.2) & nd & nd \\
\hline РCB 44 & $\mathrm{nq}$ & $\mathrm{nq}$ & $\mathrm{nq}$ & $\mathrm{nq}$ & $0.5(2.6)$ & (nd-10.5) & $1.8(1.9)$ & (nd-3.9) \\
\hline PCB 49 & $6.7(11.3)$ & (nd-47.7) & $7.1(12.6)$ & (nd-36.2) & nd (2.8) & (nd-18.1) & nd & nd \\
\hline PCB 52 & $12.4(19.2)$ & (nd-101.0) & nd (4.8) & (nd-14.6) & $5.2(6.6)$ & (nd-23.4) & $10.3(13.1)$ & $(4.2-27.4)$ \\
\hline РCB 70 & $0.7(4.0)$ & (nd-16.4) & $2.2(6.6)$ & (nd-22.2) & $4.2(4.7)$ & (nd-17.8) & $3.7(3.3)$ & (nd-5.6) \\
\hline РCB 74 & $6.0(9.4)$ & (nd-62.1) & $5.1(7.9)$ & (nd-21.7) & $\mathrm{nq}$ & $\mathrm{nq}$ & $\mathrm{nq}$ & $\mathrm{nq}$ \\
\hline PCB 82 & $5.8(11.8)$ & (nd-74.3) & $15.6(37.1)$ & $(8.1-109.3)$ & $1.2(3.2)$ & (nd-13.0) & $3.1(2.7)$ & (nd-4.6) \\
\hline PCB 87 & nd (6.9) & (nd -85.3) & nd (1.8) & (nd-7.2) & nd $(0.8)$ & (nd-5.5) & nd $(0.1)$ & (nd-0.6) \\
\hline РCB 95 & $8.6(14.4)$ & (nd-74.3) & $15.6(37.1)$ & $(8.1-109.3)$ & $1.7(5.4)$ & (nd-22.9) & $2.4(2.4)$ & (nd-4.6) \\
\hline РCB $99 / 101$ & $8.0(18.4)$ & (nd-123.1) & $13.3(19.4)$ & $(12.6-32.2)$ & $5.1(13.8)$ & (nd-56.6) & $11.9(13.1)$ & $(7.8-21.0)$ \\
\hline PCB 105/132 & $4.3(12.5)$ & (nd-105.5) & $9.5(8.3)$ & (nd-14.4) & $5.3(6.9)$ & (nd-30.6) & $4.9(4.3)$ & (nd-7.6) \\
\hline PCB 110 & $3.5(5.6)$ & (nd-23.4) & $10.3(10.8)$ & $(5.8-16.7)$ & $2.3(3.0)$ & (nd-9.1) & $1.1(1.1)$ & (nd-2.2) \\
\hline PCB 118 & $4.3(5.8)$ & (nd-17.8) & $4.7(4.2)$ & (nd-7.3) & $1.4(3.3)$ & (nd-19.5) & $3.2(3.0)$ & (nd-5.4) \\
\hline PCB 128 & nd (1.01) & (nd-6.1) & $4.5(4.0)$ & (nd-6.9) & nd (2.3) & (nd-17.9) & nd $(0.3)$ & (nd-1.2) \\
\hline PCB 138 & $14.9(17.3)$ & $(1.2-56.0)$ & $22.6(26.9)$ & $(20.0-42.2)$ & $7.2(11.3)$ & $(1.0-73.5)$ & $8.6(8.2)$ & (nd-15.4) \\
\hline PCB 149 & $15.3(20.4)$ & (nd-98.9) & $23.5(30.3)$ & $(17.5-56.8)$ & $5.9(8.9)$ & (nd-53.6) & $6.0(5.8)$ & (nd-11.1) \\
\hline PCB 151 & $0.3(4.2)$ & (nd-44.6) & $2.3(2.8)$ & (nd-6.6) & $0.9(2.3)$ & (nd-14.4) & $0.7(1.2)$ & (nd-3.3) \\
\hline PCB 153 & $19.3(20.1)$ & (nd-68.4) & $30.9(32.8)$ & $(24.0-45.4)$ & $6.8(10.7)$ & $(1.1-72.3)$ & $6.3(7.6)$ & $(3.8-13.8)$ \\
\hline PCB $156 / 171$ & nd (1.0) & (nd-16.4) & nd & nd & $4.4(5.2)$ & (nd-23.3) & (0.4) & (nd-1.5) \\
\hline PCB 158 & nd $(0.5)$ & (nd-4.5) & $2.0(1.8)$ & (nd-3.3) & nd $(0.6)$ & (nd-6.2) & $1.2(1.1)$ & (nd-2.0) \\
\hline PCB 169 & nd $(0.7)$ & (nd-18.7) & nd & nd & nd & nd & nd & nd \\
\hline PCB 170 & $6.1(6.8)$ & (nd-17.8) & $13.0(12.1)$ & $(7.9-14.4)$ & $3.3(9.0)$ & (nd-56.9) & $2.9(2.4)$ & (nd-3.8) \\
\hline PCB 177 & $4.7(5.9)$ & (nd-15.0) & $11.0(10.2)$ & $(6.2-12.3)$ & nd (3.4) & (nd-27.4) & nd & nd \\
\hline PCB 180 & $16.9(18.6)$ & (nd-51.3) & $32.8(32.2)$ & $(21.0-42.1)$ & $6.3(17.8)$ & (nd-115.0) & 9.4 (13.9) & $(6.1-30.5)$ \\
\hline PCB 183 & $5.2(5.8)$ & (nd-23.7) & $7.1(7.1)$ & $(4.9-9.5)$ & nd (1.6) & (nd-14.5) & $0.6(0.8)$ & (nd-2.0) \\
\hline PCB 187 & $10.6(11.7)$ & $(3.4-50.3)$ & $15.6(13.2)$ & (nd-21.54) & nd & nd & nd & nd \\
\hline PCB 191 & $1.6(2.3)$ & (nd-12.6) & $4.4(4.4)$ & $(2.8-5.8)$ & nd & nd & nd & nd \\
\hline PCB 194 & $2.3(2.4)$ & (nd-7.6) & $4.0(4.2)$ & $(3.7-4.9)$ & $1.3(4.3)$ & (nd-42.9) & $2.8(4.8)$ & $(1.2-12.5)$ \\
\hline PCB 195 & nd & nd & nd & nd & nd (1.0) & (nd-14.3) & nd & nd \\
\hline PCB 201/199 & $4.9(4.3)$ & (nd-10.35) & $8.2(8.2)$ & $(6.2-10.4)$ & nd (2.8) & (nd-26.9) & nd & nd \\
\hline PCB 205 & nd $(0.1)$ & (nd-1.7) & nd & nd & nd & nd & nd & nd \\
\hline PCB 206 & nd & nd & nd & nd & nd & nd & nd & nd \\
\hline PCB 208 & nd $(0.1)$ & (nd-2.9) & nd & nd & nd $(0.2)$ & (nd-3.0) & nd (0.5) & (nd-2.0) \\
\hline PCB 209 & nd & nd & nd & nd & nd & nd & nd & nd \\
\hline PCB 183 & $5.2(5.8)$ & (nd-23.7) & $7.1(7.1)$ & $(4.9-9.5)$ & nd (1.6) & (nd-14.5) & $0.6(0.8)$ & (nd-2.0) \\
\hline PCB 187 & $10.6(11.7)$ & $(3.4-50.3)$ & $15.6(13.2)$ & (nd-21.54) & nd & nd & nd & nd \\
\hline$\sum_{7} \operatorname{PCBs}\left(\mathrm{pg} \mathrm{L}^{-1}\right)$ & $88.5(96.4)$ & $(27.7-259.4)$ & $136.9(134.7)$ & $(98.7-166.1)$ & $46.2(66.1)$ & $(10.7-324.8)$ & $56.4(58.7)$ & $(41.3-80.9)$ \\
\hline$\sum_{41} \mathrm{PCBs}\left(\mathrm{pg} \mathrm{L}^{-1}\right)$ & $237.6(297.3)$ & $(82.0-931.6)$ & $417.9(421.5)$ & $(206.2-644.1)$ & $92.9(140.7)$ & $(21.4-653.8)$ & $80.4(91.7)$ & $(70.5-135.6)$ \\
\hline
\end{tabular}

nd: not detected

limited decline in PCB atmospheric concentrations for the last 15 years in the Mediterranean Sea region. There are no previous reports of the atmospheric occurrence of PCBs for the Black Sea region. In addition, the concentrations reported here for the Mediterranean atmosphere are not significantly different from those in the subtropical Atlantic Ocean (Jaward et al., 2004; Gioia et al., 2008). Nevertheless, in this study the variability of concentrations of individual congeners is higher, probably caused by the influence of the surrounding continents and the more variable atmospheric circulation patterns over the Mediterranean.

Aerosol-phase $\sum_{41}$ PCB concentrations varied from 0.8 to $35.7 \mathrm{pg} \mathrm{m}^{-3}$ in the Mediterranean Sea and from 8.3 to $19.4 \mathrm{pg} \mathrm{m}^{-3}$ in the Black Sea, with average values of 14.3 and $19.8 \mathrm{pg} \mathrm{m}^{-3}$, respectively. The maximum concentrations of aerosol-phase $\sum_{41} \mathrm{PCB}$ were found in the western
Mediterranean Sea, whereas the lowest levels were obtained in one of the samples collected in western Mediterranean (T3), and three samples from the Levantine basin (T11, $\mathrm{T} 12$ and T17). When the aerosol-phase $\sum_{41} \mathrm{PCB}$ concentrations were normalized by the concentration of aerosols $\left(C_{\mathrm{AP}}\right.$ given as $\left.\mathrm{ng} \mathrm{g}^{-1}\right)$, these ranged from 21.5 to $653.8 \mathrm{ng} \mathrm{g}^{-1}$ with an average value of $35.5 \mathrm{ng} \mathrm{g}^{-1}$ for the Mediterranean Sea, while Black Sea aerosol-phase concentrations varied from 70.5 to $35.6 \mathrm{ng} \mathrm{g}^{-1}$, exhibiting a mean concentration of $91.7 \mathrm{ng} \mathrm{g}^{-1}$. The highest aerosol-phase $\sum_{41}$ PCB concentrations, as normalized by the aerosol mass, were found in samples taken between Barcelona and Mallorca (T1 and T2), while lowest values were also detected in sample T3 and in samples taken in the Levantine basin. Therefore, the western Mediterranean Sea presented higher concentrations for particle-bound $\sum_{41} \mathrm{PCB}$ than the eastern basin, 
Table 2. Comparison of the gas-phase concentrations of the seven ICES PCB congeners in different locations of Mediterranean and Black Sea (mean $\pm \mathrm{SD}$ ) obtained in the present study with those reported previously.

\begin{tabular}{|c|c|c|c|c|c|c|c|c|}
\hline \multirow[b]{3}{*}{ Sampling year } & \multicolumn{3}{|c|}{ Atlantic Ocean } & \multicolumn{3}{|c|}{ Western Mediterranean Sea } & \multicolumn{2}{|c|}{ Eastern Mediterranean Sea } \\
\hline & \multirow{2}{*}{$\begin{array}{r}\text { Jaward et al. (2004) } \\
2001\end{array}$} & \multirow{2}{*}{$\begin{array}{r}\text { Gioia et al. (2008) } \\
2005\end{array}$} & \multirow{2}{*}{$\begin{array}{r}\text { This study } \\
2006-2007\end{array}$} & \multicolumn{2}{|c|}{ García-Flor et al. (2009) } & \multirow{2}{*}{$\begin{array}{r}\text { This study } \\
2006-2007\end{array}$} & \multirow{2}{*}{$\begin{array}{r}\text { Mandalakis and Stephanou (2002) } \\
1999-2001\end{array}$} & \multirow{2}{*}{$\begin{array}{r}\text { This study } \\
2007\end{array}$} \\
\hline & & & & 2001 & 2002 & & & \\
\hline Sample size & $N=49$ & $N=2$ & $N=3$ & $N=2$ & $N=2$ & $N=2$ & $N=37$ & $N=1$ \\
\hline PCB 28 & $12 \pm 10$ & $8.45 \pm 7.0$ & $4.3 \pm 5.4$ & $17.6 \pm 18.2$ & $47.45 \pm 6.2$ & - & $5.01 \pm 3.48$ & - \\
\hline PCB 52 & $6 \pm 5$ & $3.05 \pm 1.8$ & $5.2 \pm 4.5$ & $58.3 \pm 19.5$ & $42.45 \pm 28.5$ & $71.5 \pm 41.7$ & $4.36 \pm 2.70$ & 12.6 \\
\hline PCB 101 & $1.4 \pm 4$ & $1 \pm 0.3$ & $9.0 \pm 12.1$ & $25.5 \pm 22.1$ & $16.1 \pm 19.5$ & $70.5 \pm 74.3$ & $3.74 \pm 2.80$ & 1.2 \\
\hline PCB 118 & $1.5 \pm 1.5$ & $2.1 \pm 0.4$ & $4.5 \pm 0.4$ & $17.2 \pm 5.6$ & $32.1 \pm 40.9$ & $7.9 \pm 11.2$ & $1.48 \pm 1.31$ & - \\
\hline PCB 138 & $2.9 \pm 2.3$ & $1.95 \pm 0.6$ & $5.4 \pm 3.6$ & $36.0 \pm 21.4$ & $15.55 \pm 8.1$ & $41.1 \pm 21.0$ & $0.72 \pm 0.35$ & 7.4 \\
\hline PCB 153 & $6.1 \pm 5$ & $0.6 \pm 0.1$ & $5.6 \pm 5.0$ & $46.7 \pm 27.2$ & $8.8 \pm 10.2$ & $51.8 \pm 23.5$ & $1.47 \pm 0.74$ & 7.4 \\
\hline PCB 180 & $1.2 \pm 0.87$ & $3.15 \pm 1.2$ & $2.3 \pm 4.1$ & $8.9 \pm 1.5$ & $17.9 \pm 16.8$ & $17.5 \pm 1.1$ & $0.41 \pm 0.24$ & 7.2 \\
\hline
\end{tabular}

either normalized by filtered volume or amount of particles, being Barcelona and Mallorca the regions showing higher $C_{\mathrm{AP}}$ values. Particle-bound $\sum_{\text {7ICES }} \mathrm{PCBs}$ varied from 0.4 to $17.9 \mathrm{pg} \mathrm{m}^{-3}$ in the Mediterranean Sea and from 4.5 to $11.55 \mathrm{pg} \mathrm{m}^{-3}$ in the Black Sea, accounting for 47 and $57 \%$ of the $\sum_{41}$ PCB respectively These concentrations are in the lower range of those concentrations reported for low populated coastal regions of the northwestern Mediterranean Sea (García-Flor et al., 2009) and in the same range of those measured in an eastern Mediterranean Sea coastal station (Mandalakis et al., 2005).

The average levels of mono-ortho substituted PCBs (dioxin-like congeners) in both gas and aerosol phases were generally lower than for the rest of PCB congeners, with average concentrations ranging from 0.03 to $1.53 \mathrm{pg} \mathrm{m}^{-3}$, and from 0.001 to $0.2 \mathrm{pg} \mathrm{m}^{-3}$, respectively (Table 3). The concentrations in all the cases were fairly constant, showing non-significant spatial variations neither in the gas nor in the aerosol phases. The long sampling time periods for this subset of samples (4 days) may have produced an averaging of the air masses from different origins leading to the observed lack of variability. There are no data available for mono-ortho PCBs congeners in the literature for the Mediterranean Sea. However, the values reported here were generally lower than the atmospheric concentrations reported for the same congeners in a coastal Mediterranean lagoon (1-7 and $0.1-0.6 \mathrm{pg} \mathrm{m}^{-3}$ gas- and aerosol-phase levels, respectively) (Castro-Jiménez et al., 2011).

The gas-phase concentrations of HCB varied from limit of detection (LOD) to $418.3 \mathrm{pg} \mathrm{m}^{-3}$ (mean of $54.4 \mathrm{pg} \mathrm{m}^{-3}$ ), with higher concentrations in the western than in the eastern Mediterranean. The highest $C_{\mathrm{G}}$ for HCB was detected in sample STIIa collected between Mallorca and Sardinia. The average HCB concentrations for the Mediterranean and Black seas (59.2 and $42.0 \mathrm{pg} \mathrm{m}^{-3}$ respectively) are in agreement with measures performed by other studies in the Mediterranean region (Albaigés et al., 2005) and the Atlantic Ocean (Jaward et al., 2004; Lohmann et al., 2009), even though we observed a larger variability in concentrations.

The aerosol-phase HCB varied from non-detected to $0.7 \mathrm{pg} \mathrm{m}^{-3}$, with an average value of $0.1 \mathrm{pg} \mathrm{m}^{-3}$. Samples with no HCB were located in the Levantine basin and Black Sea whereas the maximum value was measured in the the Sea of Marmara, near the city of Istanbul. Particle-normalized aerosol-phase HCB concentrations did not show any significant spatial variations with the exception of two peak values in samples collected between Barcelona and Mallorca, and near Istanbul. There are no previous studies of aerosol-phase $\mathrm{HCB}$ for the Mediterranean atmosphere.

\subsection{Aerosol bulk composition and aerosol-gas partitioning of PCBs and $\mathrm{HCB}$}

A principal component analysis (PCA) was performed for congener groups to assess the variability of PCBs in the aerosol phase (see Supplement E). When using volumetric concentrations $\left(\mathrm{pg} \mathrm{m}^{-3}\right)$, the first two principal components (PC1 and PC2) explaining 41 and $30 \%$ of the variability, respectively, separated samples in a gradient of concentrations (see Supplement E). In addition, two groups of samples were differentiated from the rest of samples, both of them characterized by the highest $C_{\mathrm{AP}}$ levels. This discrimination between sample groups was also well defined when the PCA was generated with particle-normalized concentrations (in $\mathrm{ng} \mathrm{g}^{-1}$ ). The first group was comprised by samples located between Barcelona and Mallorca (T1 and T2), consistent with the influence of the air masses coming from the industrialized and populated coast of Catalonia (NW Mediterranean). The content of the organic and black carbon in atmospheric particles, which favors elevated concentrations of POPs in the aerosol phase, was relatively higher for these samples ( $f_{\mathrm{OC}}$ of 0.11 and $f_{\mathrm{BC}}$ of 0.017 ), and within the range of previously described coastal/urban aerosols (Dachs and Eisenreich, 2000; Querol et al., 2009). The second set of samples differentiated by the PCA analysis included samples collected between Mallorca and Sardinia, with air masses associated with back-trajectories indicating an Atlantic/North African origin (ST1b, STIIb, T4 and T5). Saharan dust events occurred when these samples were collected (see Supplement E). Other studies have described high concentrations of POPs associated with dust events (Garrison et al., 2013). 
Table 3. Mono-ortho substituted PCB congeners in gas and aerosol phase in $\mathrm{pg} \mathrm{m}^{-3}$.

\begin{tabular}{lcccc|cccc}
\hline & \multicolumn{3}{c|}{ Gas phase $(N=18)$} & \multicolumn{3}{c}{ Aerosol phase $(N=18)$} \\
\cline { 2 - 9 } & Average & Median & Min & Max & Average & Median & Min & Max \\
\hline PCB 105 & 0.590 & 0.576 & 0.348 & 1.183 & 0.080 & 0.056 & 0.011 & 0.303 \\
PCB 114 & 0.075 & 0.067 & 0.041 & 0.142 & 0.009 & 0.009 & 0.001 & 0.021 \\
PCB 118 & 1.530 & 1.468 & 0.938 & 3.030 & 0.204 & 0.133 & 0.029 & 0.825 \\
PCB 123 & 0.030 & 0.029 & 0.015 & 0.056 & 0.004 & 0.002 & 0.001 & 0.017 \\
PCB 156 & 0.291 & 0.300 & 0.153 & 0.452 & 0.075 & 0.049 & 0.011 & 0.184 \\
PCB 157 & 0.033 & 0.030 & 0.020 & 0.064 & 0.009 & 0.007 & 0.002 & 0.025 \\
PCB 167 & 0.144 & 0.144 & 0.075 & 0.217 & 0.033 & 0.022 & 0.005 & 0.093 \\
PCB 189 & 0.031 & 0.032 & 0.016 & 0.046 & 0.010 & 0.008 & 0.002 & 0.029 \\
\hline
\end{tabular}

Gas-particle partitioning is an important mechanism affecting POPs' fate and transport within the atmosphere, since dominant atmospheric depositional processes and the relative contribution of different degradation mechanisms differ between the gas- and aerosol-phase compounds (Anderson and Hites, 1996; Mandalakis et al., 2003). The aerosol-gas partition coefficient $\left(K_{\mathrm{P}}\right)$ is given by

$K_{\mathrm{P}}=\frac{C_{\mathrm{AP}}}{C_{\mathrm{G}} \mathrm{TSP}}=\frac{f_{\mathrm{OC}}}{\rho_{\mathrm{OCT}}}\left(\frac{\gamma_{\mathrm{OCT}} \mathrm{MW}_{\mathrm{OCT}}}{\gamma_{\mathrm{OC}} \mathrm{MW}_{\mathrm{OC}}}\right) K_{\mathrm{OA}}$,

where TSP is the concentration of total suspended particles $\left(\mu \mathrm{g} \mathrm{m}^{-3}\right), f_{\mathrm{OC}}$ is the fraction of organic carbon in the aerosol, $\gamma_{\mathrm{OCT}}$ and $\gamma_{\mathrm{OC}}$ are the activity coefficients of PCBs in octanol and the aerosol organic carbon, respectively, $\mathrm{MW}_{\mathrm{OCT}}\left(\mathrm{g} \mathrm{mol}^{-1}\right)$ and $\mathrm{MW}$ OC $\left(\mathrm{g} \mathrm{mol}^{-1}\right)$ are the molecular weight of octanol and aerosol organic carbon, and $K_{\mathrm{OA}}$ is the temperature-corrected octanol-air partition coefficient as reported elsewhere (Harner and Bidleman, 1996; Kömp and McLachlan, 1997; Shoeib and Harner, 2002). Figure 3 (and Supplement E) shows the correlation between $K_{\mathrm{P}}$ and $K_{\mathrm{OA}}$ assuming that the value of $\gamma_{\mathrm{OCT}} \mathrm{MW}$ OCT $/ \gamma_{\mathrm{OC}} \mathrm{MW}_{\mathrm{OC}}$ equals unity, an assumption discussed below.

There was a significant correlation $(p<0.05)$ between $K_{\mathrm{P}}$ and $K_{\mathrm{OA}}$ when considering $\mathrm{HCB}$ and all the measured PCBs, but it only explained $26 \%$ of the variability and the slope was significantly lower than one (Supplement E). Nevertheless, if only HCB and tri- to pentachlorinated PCB congeners were considered, the fitted least-squares regression line explained $75 \%$ of the variability and the slope was close to unity (Fig. 3). Conversely, congeners with a higher chlorinated degree did not show the same trend, since the $K_{\mathrm{P}}$ values for these compounds did not further increase as the corresponding $K_{\mathrm{OA}}$ increased. PCB congeners with six or more $\mathrm{Cl}$ fitted to a regression line with a slope significantly less than unity (Fig. 3). Previous reports of the gas-particle partitioning of PCBs have also described slopes between $K_{\mathrm{P}}$ and $K_{\mathrm{OA}}$ significantly lower than unity in continental environments (Mandalakis and Stephanou, 2007; Radonić et al., 2011), even though slopes close to unity have been re-

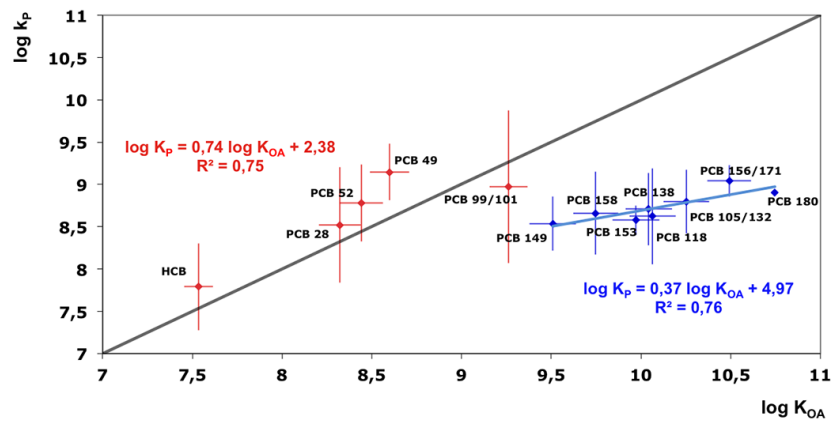

Figure 3. Aerosol-particle partitioning of PCBs and HCB. Log$\log$ relationship between aerosol-gas partition coefficient $\left(K_{\mathrm{P}}\right)$ and octanol-air partitioning coefficient $\left(K_{\mathrm{OA}}\right)$ for $\mathrm{PCB}$ and HCB. $K_{\mathrm{OA}}$ values were corrected for temperature.

ported for PCBs in urban atmospheres (Harner and Bidleman, 1998).

For aerosol-gas partitioning close to equilibrium, the slope of the correlation $\log \mathrm{K}_{\mathrm{P}}-\log K_{\mathrm{OA}}$ is expected to have a value near unity. Therefore, a slope lower than unity in the relationship between $K_{\mathrm{P}}$ and $K_{\mathrm{OA}}$ could be explained by differential values in $\gamma_{\mathrm{OCT}} \mathrm{MW}$ OCT $/ \gamma_{\mathrm{OC}} \mathrm{MW}_{\mathrm{OC}}$ for the different congeners, which in turn, assuming the same value of $\mathrm{MW}_{\mathrm{OC}}$, could be driven by the differential values of $\gamma_{\mathrm{OC}} \mathrm{de}-$ pending on the compound as suggested elsewhere (Goss and Schwarzenbach, 1998). In addition to varying values of $\gamma_{\mathrm{OM}}$, however, it is likely that there is a lack of aerosol-gas equilibrium for the higher chlorinated congeners, with aerosolphase concentrations lower than those in equilibrium. The kinetics of sorption is faster for the less chlorinated PCB congeners and HCB than for the more chlorinated congeners. For example, emissions of sea spray aerosol that has not yet been equilibrated with the gas phase could lead to shallow slopes. 


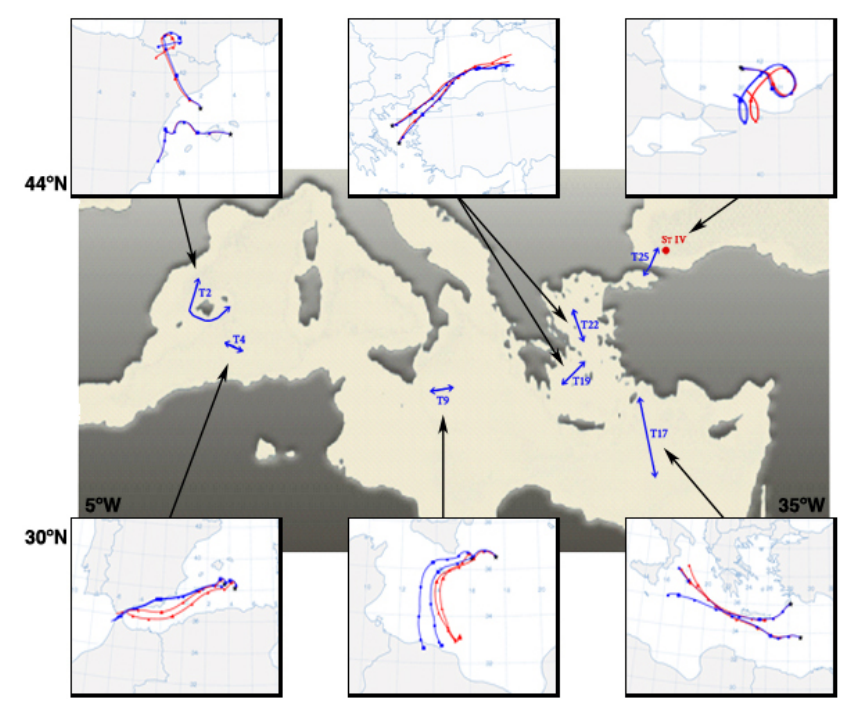

Figure 4. Air mass back-trajectories $(48 \mathrm{~h})$ of selected samples at two different heights ( $15 \mathrm{~m}$ in red and $100 \mathrm{~m}$ in blue) obtained with the HYSPLIT model. Upper panels' back-trajectories correspond to samples with the higher PCB concentrations (T2, T19, T22, T25, STIVa, STIVb and STIVc) whereas the lower panels correspond to air masses with lower $C_{\mathrm{G}}$ (T4, T9 and T17).

\subsection{Factors affecting the atmospheric occurrence of PCBs and HCB}

A principal component analysis (PCA) was carried out for congener groups (sum of the PCB congeners with the same degree of chlorination) in the gas phase (see Supplement F). The two first principal components (PC1 and PC2), explaining 35 and $23 \%$ of the variability respectively, separate samples in a gradient of concentrations. Samples T4, T9, T17 and STI show the lowest $C_{\mathrm{G}}$ for $\sum_{41} \mathrm{PCB}$, while T2, T22, T25, STV and T12 were those samples with the highest $C_{\mathrm{G}}$.

For the sampling period of this study, the temperature influence on PCBs and HCB gas-phase concentrations was evaluated using the Clausius-Clapeyron equation (see Supplement F). Nevertheless, unlike land-based studies, the results did not show any significant correlation between gasphase concentrations and temperature for any of the compounds, which is in agreement with other measurements in oceanic regions (Mandalakis and Stephanou, 2002; Lohmann et al., 2009). On the one hand, the temperature range during the cruises was possibly too tight to highlight the temperature dependence on the partial pressure of the compounds. The seawater temperatures showed a narrow range of variability $\left(20^{\circ} \mathrm{C} \pm 3\right)$. On the other hand, this temperature dependence is more marked in land where temperature-dependent reemissions from other compartments such as soils are much stronger than from the marine environment. Indeed, after long-range atmospheric transport, the temperature dependence of gas-phase concentrations observed in source regions is lost due to dilution and depositional processes (Wania et al., 1998, Galbán-Malagón et al., 2013). Even though temperature alone does not influence significantly the gas-phase concentrations, it contributes to the third principal component (Table S11 in the Supplement F) of the statistical analysis explaining $15 \%$ of the variability.

In order to examine the influence of the origin of air masses on $C_{\mathrm{G}}$, back-trajectories were evaluated for these two sub-sets of samples with extreme values of $C_{\mathrm{G}}$. The Mediterranean region has a complicated atmospheric circulation pattern characterized by a strong northern component, which is particularly pronounced during the warm periods of the year. This is due to differential heating between the land of North Africa (almost bare soil), the Mediterranean waters and the land of southern Europe with vegetation cover (UNEP, 2002). This circulation pattern is reflected by the back-trajectories for the sample transects in this study (see Supplement B).

Figure 4 shows the air-mass back-trajectories corresponding to the samples with the lowest $C_{\mathrm{G}}$ (lower panels in Fig. 4) and higher $C_{\mathrm{G}}$ (upper panels of Fig. 4) for the $\sum_{41}$ PCB. The lowest $C_{\mathrm{G}}$ values corresponded to sampling periods with predominant marine-influenced air masses. Conversely, the highest concentrations were associated with land-based air masses from the north (Europe). These trends can be explained as the result of the contribution of POPs' primary and secondary sources, in addition to the depositional and degradative processes. On the one hand, when air masses encounter land surfaces they could have potentially received OCls from the terrestrial reservoirs. Populated coastal regions and large industrial areas are possible sources of PCBs to the atmosphere (García-Flor et al., 2009) where large reservoirs of these chemicals still remain. For example, soils are the major environmental reservoir of previously emitted and re-deposited POPs (Dalla Valle et al., 2005), and could be acting as a secondary source of $\mathrm{OCl}$ to the atmosphere (Jones and De Voogt, 1999). Volatilization of PCBs and HCB from soils is enhanced during warm periods (Gouin et al., 2002), and they could be an important source of OCls to the regional atmosphere (Cabrerizo et al., 2011a, b). Therefore, the higher PCB concentrations for the sampling periods dominated by air masses from Europe could be driven by these southern European OCl sources. On the other hand, the lowest concentrations were associated with air masses of marine origin (Fig. 4). During atmospheric transport, a dilution process of $\mathrm{OCl}$ levels occurs as distance from the source increases. The strength of this dilution mechanism is modulated by depositional and degradative fluxes influencing air masses traveling over the sea and can be assessed calculating the atmospheric residence times for the different compounds.

\subsubsection{Atmospheric residence times over the Mediterranean Sea}

The burden and fate of PCBs and HCB in the marine atmospheric environment can be affected by a number of physical and biogeochemical variables that in turn will be determining 
the atmospheric residence times of the compounds. The atmospheric resident times $(R, d)$ were estimated following the approach proposed elsewhere (Jurado and Dachs, 2008):

$$
R=\frac{C_{\mathrm{TOTAL}}}{F_{\mathrm{OH}}+F_{\mathrm{DD}}+F_{\mathrm{WD}}+F_{\mathrm{AWdep}}+F_{\mathrm{AWvol}}} \cdot \mathrm{AML},
$$

where $C_{\text {TOTAL }}$ is the total concentration of POPs in the atmosphere (gas and aerosol phase), AML is the considered atmospheric mixed layer height, and $F_{\mathrm{OH}}, F_{\mathrm{DD}}, F_{\mathrm{WD}}, F_{\mathrm{AWdep}}$ and $F_{\mathrm{AWvol}}$ are the atmospheric $\mathrm{OH}$ degradation flux, atmospheric dry deposition flux, atmospheric wet deposition flux, diffusive deposition flux and diffusive volatilization flux, respectively. The volatilization from the underlying sea surface is the only input of OCls to the atmosphere of the sea regions away from the shore. Wet deposition process was in this case not considered due to lack of rainfall events during the sampling cruise. On average, $R$ ranged from 1.2 days for less chlorinated compounds (PCB 18), to 3.9 days for more chlorinated congeners (PCB 187), whereas HCB atmospheric resident time was much higher, up to 53 days due to the extreme persistence of HCB in the atmosphere and close to equilibrium air-water conditions. The short atmospheric residence times for PCBs do not contradict the apparent lack of decline in PCB concentrations over the Mediterranean during the last 15 years. The long-term trends depend on the remaining primary sources and the concentrations in the different reservoirs acting as secondary sources (soil, vegetation, ocean, atmosphere). The short values for $R$ estimated here are indicative that once PCBs are present in the atmosphere their concentrations decrease after a few days of atmospheric transport over the sea due to different deposition and degradation processes, whereas the lack of a long-term decrease implies that there are large continuous primary and secondary sources of PCBs that supply and support the atmospheric occurrence of PCBs and HCB to the Mediterranean atmosphere.

To evaluate the critical process affecting the magnitude of the residence times for the different compounds, Eq. (5) was parameterized as (see Supplement F for details)

$$
\begin{aligned}
& R= \\
& {\left[\frac{1}{r_{\mathrm{OH}} \mathrm{AML}(1-\emptyset)}+\frac{1}{v_{\mathrm{DD}} \emptyset}+\frac{1}{k_{\mathrm{AW}} \frac{(1-\emptyset)}{H^{\prime}}}-\frac{1}{\left(k_{\mathrm{AW}}-k_{\mathrm{ADW}}\right) \frac{(1-\emptyset)}{H^{\prime}}}\right] \mathrm{AML},}
\end{aligned}
$$

where $\emptyset$ is the fraction of $\mathrm{OCl}$ bound to the aerosols in the atmosphere, $r_{\mathrm{OH}}$ is the compound-specific $\mathrm{OH}$ radical degradation decay rate $\left(\mathrm{d}^{-1}\right)$, and $k_{\mathrm{ADW}}$ is the air-deep-water mass transfer coefficient estimated as reported elsewhere (Dachs et al., 2002). The latter is strongly dependent on the magnitude of the biological pump removing PCBs from surface waters and the lower atmosphere. Below we discuss each of these removing processes of PCBs and HCB from the lower atmosphere.

\subsubsection{Atmospheric degradation due to $\mathrm{OH}$ radicals}

$\mathrm{OCl}$ degradation in the atmosphere is dominated by the reaction with hydroxyl radicals and occurs mainly in the gasphase (Anderson and Hites, 1996; Jurado and Dachs, 2008). The degradation decay rate can be calculated as follows:

$r_{\mathrm{OH}}=k_{\mathrm{OH}} C_{\mathrm{OH}}$,

where $C_{\mathrm{OH}}\left(\right.$ molecules $\left.\mathrm{cm}^{-3}\right)$ is the atmospheric concentration of $\mathrm{OH}$ radicals and $k_{\mathrm{OH}}\left(\mathrm{cm}^{3}\right.$ molecules $\left.{ }^{-1} \mathrm{~s}^{-1}\right)$ is the degradation rate constant reported by Anderson and Hites (1996) and Mandalakis et al. (2003) for PCBs, and Brubaker and Hites (1998) for HCB. The atmospheric concentration of $\mathrm{OH}$ radicals above the Mediterranean was assumed to be $8 \times 10^{6}$ molecules $\mathrm{cm}^{-3}$, a value comparable with the concentrations reported for latitudes between 28 and $44^{\circ} \mathrm{N}$ (Spivakovsky et al., 2000), and the $\mathrm{OH}$ concentrations reported for the eastern Mediterranean during summer (Mandalakis et al., 2003). Gas-phase PCB congeners containing five and six chlorine atoms showed the highest relative abundance in the gas phase, accounting for 50 and $60 \%$ of $\sum_{41} \mathrm{PCB}$ in the atmosphere of the Mediterranean and Black seas, respectively. This contrasts with other studies that have reported higher abundance of dichlorinated and trichlorinated congeners in oceanic atmospheres (Jaward et al., 2004; Gioia et al., 2008). The described decrease in the relative abundance of the less chlorinated compounds could be explained by $\mathrm{PCB}$ depletion due to $\mathrm{OH}$ radicals present in the atmosphere, a process that is relatively faster for the less chlorinated congeners (Anderson and Hites, 1996) as indicated by the corresponding degradation rate constant. Mandalakis and coworkers (Mandalakis et al., 2003) have already suggested this process to explain the compound profile found in an eastern Mediterranean atmosphere, where a relative decrease of dichlorinated and trichlorinated congeners was observed in comparison to tetrachlorinated and pentachlorinated congeners during the summer period and periods of high $\mathrm{OH}$ radical concentrations (Mandalakis and Stephanou, 2002; Mandalakis et al., 2003). HCB degradation rate constants on the contrary are 1 order of magnitude lower than for PCB, thus resulting in longer $R$ values.

\subsubsection{Atmospheric deposition of PCBs and HCB}

Figure 5a shows the dry deposition fluxes for the different Mediterranean sub-basins. Due to the assumption of a unique value of $v_{\mathrm{D}}$ for all sampling events, the spatial pattern of $F_{\mathrm{DD}}$ equals that of the aerosol-phase concentrations (Fig. 2), with higher $F_{\mathrm{DD}}$ values for the western Mediterranean basin. As commented above, higher aerosol-phase concentrations of PCBs were also found associated with dust events. The association of PCBs and other POPs to dust aerosols has been poorly characterized in terms of their deposition fluxes, but large dust particles may deposit with $v_{\mathrm{D}}$ values much higher than those assumed here. Therefore, it is possible that 


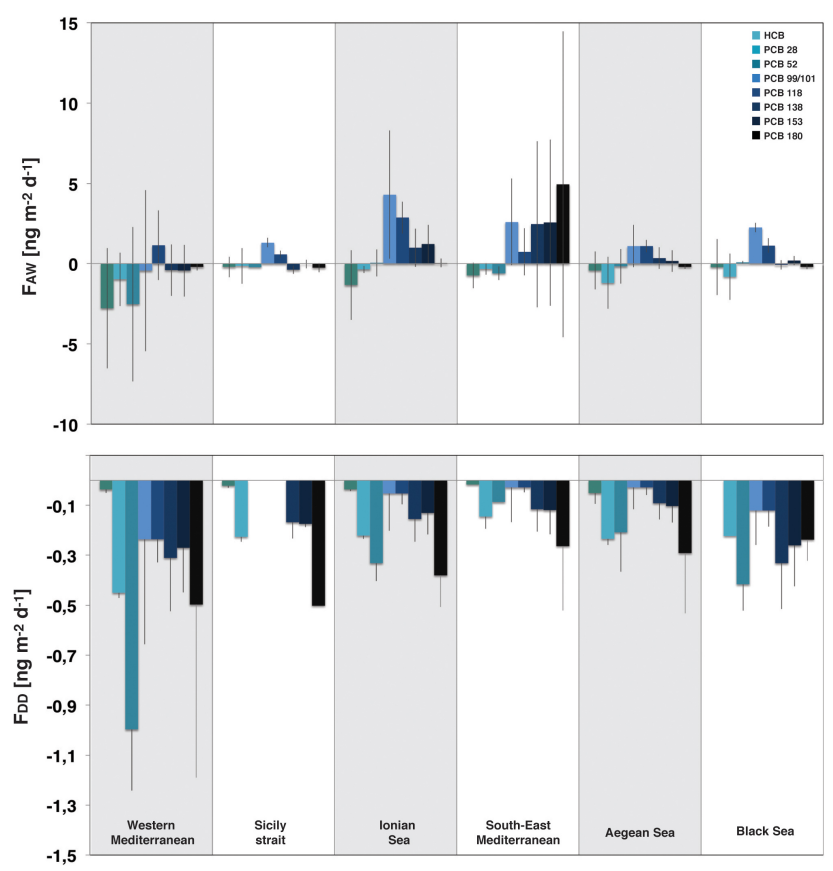

Figure 5. Atmospheric deposition of polycyclic aromatic hydrocarbons: (lower panel) dry deposition fluxes for the different Mediterranean basins; (upper panel) diffusive air-water exchange for the different Mediterranean basins.

we are underestimating the dry deposition fluxes associated with dust-driven deposition by 1 order of magnitude, and thus overestimating the atmospheric resident times for periods with Saharan dust events.

Supplement Fig. S15 shows the box plot of $f_{\mathrm{G}} / f_{\mathrm{W}}$ for each PCB congener. Most PCB congeners are found very close to dynamic air-water equilibrium, with a predominance of net diffusive deposition over volatilization episodes. Figure 5 shows the air-water diffusive fluxes (Fig. 5b) and their comparison with the dry deposition fluxes, evidencing the greater importance of diffusive exchanges due to the fact that PCBs and HCB are mostly found in the gas phase. In fact, the amount of PCBs and HCB associated with particles in our study was very low and on average accounted for the $6 \%$ of the total atmospheric concentration. This is in agreement with previous studies performed in the same region (Mandalakis and Stephanou, 2002; García-Flor et al., 2009) and in other oceanic regions (Galbán-Malagón et al., 2012). Nevertheless, while the eastern basin presents a clear predominance of gas-phase PCBs (91-99.6\%), the variability in the western basin is higher due to higher aerosol loads for some sampling periods, with a maximum of particle-bound PCBs of $24 \%$ of the total atmospheric PCBs.

\subsubsection{Biogeochemical characteristic of the underlying water column}

Water column biogeochemistry plays a critical role in controlling the dissolved phase concentration, and thus the airwater gradient of POP concentrations (Dachs et al., 2002). Previous studies have already assessed the role of the biological pump as one of the key mechanisms governing the sink of hydrophobic and persistent pollutants, such as PCBs or polybrominated diphenyl ethers (PBDEs) in oceanic (Dachs et al., 2002; Jaward et al., 2004; Galbán-Malagón et al., 2012) and lacustrine environments (Dachs et al., 1999; Nizzetto et al., 2012). In fact, air-water exchange and partitioning to/uptake by planktonic organisms (particularly phytoplankton) and other pools of particulate organic matter could act as coupled processes in aquatic environments (Dachs et al., 2002). Once atmospheric POPs enter the dissolved phase through airwater diffusion exchange, they partition to particles and/or planktonic organisms, and they can be removed from the surface waters and delivered to the deep ocean by sinking particles and/or zooplanktonic vertical migrations. Driven by these losses, air-water disequilibria can be enhanced, which is particularly important for hydrophobic chemicals and in situations with higher amounts of biomass. A companion study (Berrojalbiz et al., 2011) showed field evidence of the relevance of these processes as a driver of PCB water column concentrations in the Mediterranean Sea.

The described scenario is consistent with the results found here, where, for the time periods with the higher plankton biomass, the gas-phase concentrations were at the lower end of those observed (Supplement Fig. S16). However, most of the sampling periods correspond to areas with biomass within a very narrow range and low biomass values, which does not allow for further assessment of this interaction between water column biogeochemistry and the atmospheric occurrence of POPs in the Mediterranean. Unlike other oceanic regions, the Mediterranean Sea is oligotrophic (Regaudie-de-Gioux et al., 2009), and thus the biological pump has a much lower potential to deplete the dissolved concentrations in surface waters and drive air and water out of equilibrium as has been observed for the North Atlantic and Southern Ocean (Galbán-Malagón et al., 2012, 2013). Conversely, close to air-water equilibrium conditions for PCBs have also been described for the oligotrophic Atlantic and Pacific oceans (Gioia et al., 2008; Zhang and Lohmann, 2010), consistent with the results reported here.

\subsubsection{Relative contribution of processes controlling the OCl atmospheric burden}

Among the different loss processes affecting the atmospheric residence times of PCBs, there is a clear dominance of the influence of $\mathrm{OH}$ radical degradation in the atmosphere over the rest of the processes. Figure 6 shows the integrated atmospheric loss fluxes $\left(\mathrm{kg} \mathrm{month}^{-1}\right)$ of PCBs and HCB due to 


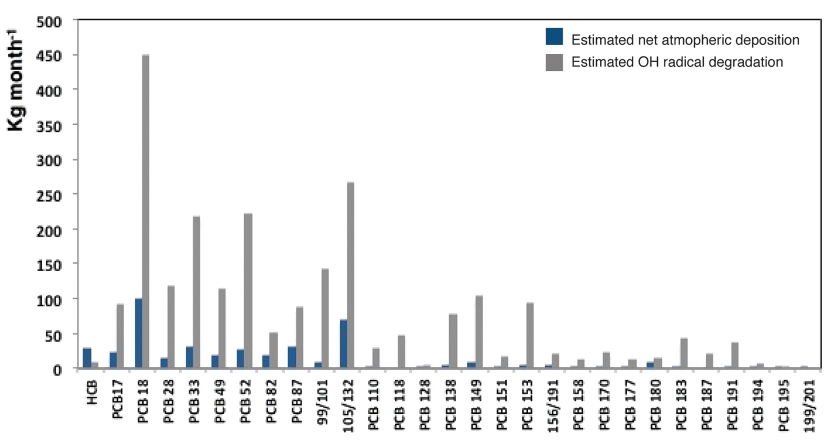

Figure 6. Comparison of losses of atmospheric PCBs and $\mathrm{HCB}$ due to atmospheric deposition and degradation by reaction with $\mathrm{OH}$ radicals during the summer. Fluxes are given as integrated for the whole Mediterranean basin.

reaction with $\mathrm{OH}$ radicals and atmospheric deposition during the summer. The oligotrophic characteristics of the Mediterranean surface waters do not pose importance to the contribution of the biological pump that could potentially alter airwater diffusive exchange toward a net deposition flux - thus atmospheric deposition during the summer is less important as a depletion mechanism for atmospheric concentrations of $\mathrm{PCBs}$ than degradation due to reaction with $\mathrm{OH}$ radicals. Nevertheless, during the spring season, the Mediterranean Sea is subjected to important planktonic blooms (Turley et al., 2000) with significantly higher planktonic biomass where it is likely to produce an increase in the relative importance of the biological pump on the decrease of the atmospheric resident times of POPs. Moreover, $\mathrm{OH}$ radical degradation is strongly dependent on the temperature and radiation (Anderson and Hites, 1996; Mandalakis et al., 2003), and thus it is expected to decrease to a great extent during winter season $(\mathrm{OH}$ radical concentration is 5 to 10 times lower than in summer periods) (Spivakovsky et al., 2000). Likewise, wet deposition processes not measured in this work should also be considered to be an important variable in more rainy seasons of the year and for some Mediterranean sub-basins not sampled during the THRESHOLDS cruises.

\section{Conclusions}

The present study has generated an extensive and unique data set of gas and aerosol-phase concentrations of OCls in the Mediterranean atmosphere. Concentrations are lower than those reported over the adjacent continents, but there is a large variability in concentrations. Higher concentrations were observed for periods with air masses from the northern basin, while the minimum concentrations were observed when the air masses had a marine origin. Dry deposition, airwater diffusive fluxes and degradation with $\mathrm{OH}$ radical fluxes have been estimated. There is a close to air-water equilibrium for most periods and PCB congeners, even though there is a net deposition in some periods. Degradation with $\mathrm{OH}$ radicals is the major loss process of PCBs during the summer months. Conversely, the atmospheric residence times of HCB are long due to a lack of effective atmospheric degradation and deposition.

\section{The Supplement related to this article is available online at doi:10.5194/acp-14-8947-2014-supplement.}

Acknowledgements. This work was funded by the European Union and Spanish Ministry of Science and Innovation through the THRESHOLDS projects. N. Berrojalbiz acknowledges a predoctoral fellowship from the Basque Government.

Edited by: R. Ebinghaus

\section{References}

Albaigés, J.: Persistent organic pollutants in the Mediterranean Sea, in: The Mediterranean Sea, Springer, Berlin, Heidelberg, 89149, 2005.

Anderson, P. N. and Hites, R. A.: OH radical reactions: The major removal pathway for polychlorinated biphenyls from the atmosphere, Environ. Sci. Technol., 30, 1756-1763, 1996.

Bamford, H. A., Poster, D. L., Huie, R., and Baker J. E.: Using extrathermodynamic relationships to model the temperature dependence of Henry's law constants of 209 PCB congeners, Environ. Sci. Technol., 36, 4395-4402, doi:10.1021/es020599y, 2002.

Berrojalbiz, N., Dachs, J., Del Vento, S., Ojeda, M. J., Valle, M. C., Castro-Jiménez, J., Mariani, G., Wollgast, J., and Hanke, G.: Persistent organic pollutants in mediterranean seawater and processes affecting their accumulation in plankton, Environ. Sci. Technol., 45, 4315-4322, 2011.

Bidleman, T.: Atmospheric transport and air surface exchange of pesticides, Water Air. Soil. Poll., 115, 115-166, 1999.

Birch, M. E. and Cary, R. A.: Elemental carbon-based method for monitoring occupational exposures to particulate diesel exhaust, Aerosol Sci. Tech., 25, 221-241., 1996.

Breivik, K., Sweetman, A., Pacyna, J. M., and Jones, K. C.: Towards a global historical emission inventory for selected PCB congeners - a mass balance approach: 2. Emissions, Sci. Total Environ., 290, 199-224, 2002.

Brubaker W. W. and Hites, R. A.: OH Reaction Kinetics of GasPhase $\alpha$ - and $\gamma$-Hexachlorocyclohexane and Hexachlorobenzene, Environ. Sci. Technol., 32, 766-769, 1998.

Bruhn, R., Lakaschus, S., and McLachlan, M. S.: Air-sea gas exchange of PCBs in the southern Baltic Sea, Atmos. Environ. 37 , 3445-3454, 2003.

Cabrerizo, A., Dachs, J., Moeckel, C., Ojeda, M. J., Caballero, G., Barcelo, D., and Jones, K. C.: Factors influencing the soil-air partitioning and the strength of soils as a secondary source of polychlorinated biphenyls to the atmosphere, Environ. Sci. Technol., 45, 4785-4792, 2011a.

Cabrerizo, A., Dachs, J., Jones, K. C., and Barceló, D.: Soil-Air exchange controls on background atmospheric concentrations 
of organochlorine pesticides, Atmos. Chem. Phys., 11, 1279912811, doi:10.5194/acp-11-12799-2011, 2011b.

Castro-Jiménez, J., Eisenreich, S. J., Ghiani, M., Mariani, G., Skejo, H., Umlauf, G., Wollgast, J., Zaldívar, J. M., Berrojalbiz, N., Reuter, H. I., and Dachs, J.: Atmospheric occurrence and deposition of polychlorinated dibenzo-p-dioxins and dibenzofurans (PCDD/Fs) in the open Mediterranean Sea, Environ. Sci. Technol., 44, 5456-5463, 2010.

Castro-Jiménez J., Mariani, G., Vives I., Skejo, H., Umlauf, G., Zaldivar, J. M., Dueri, S., Messiaen, G., and Laugier, T.: Atmospheric concentrations, occurrence and deposition of persistent organic pollutants (POPs) in a Mediterranean coastal site (Etang de Thau, France), Environ. Pollut., 159, 1948-1956, 2011.

Dachs, J. and Eisenreich S. J.: Adsorption onto aerosol soot carbon dominates gas-particle partitioning of polycyclic aromatic hydrocarbons, Environ. Sci. Technol., 34, 3690-3697, 2000.

Dachs, J., Eisenreich, S. J., Baker, J. E., Ko, F. C., and Jeremiason, J. D.: Coupling of phytoplankton uptake and air-water exchange of persistent organic pollutants, Environ. Sci. Technol., 33, 36533660, 1999.

Dachs, J., Lohmann, R., Ockenden, W. A., Méjanelle, L., Eisenreich, S. J., and Jones K. C.: Oceanic biogeochemical controls on global dynamics of persistent organic pollutants, Environ. Sci. Technol., 36, 4229-4237, 2002.

Dalla Valle, M., Jurado, E., Dachs, J., Sweetman, A. J., and Jones, K. C.: The maximum reservoir capacity of soils for persistent organic pollutants: implications for global cycling, Environ. Pollut., 134, 153-64, 2005.

Del Vento, S. and Dachs, J.: Atmospheric occurrence and deposition of polycyclic aromatic hydrocarbons in the northeast tropical and subtropical Atlantic Ocean, Environ. Sci. Technol., 41, 5608-5613, 2007a.

Del Vento, S. and Dachs J.: Influence of the surface microlayer on atmospheric deposition of aerosols and polycyclic aromatic hydrocarbons, Atmos. Environ., 41, 4920-4930, 2007 b.

Galbán-Malagón, C., Berrojalbiz, N., Ojeda, M. J., and Dachs, J.: The oceanic biological pump modulates the atmospheric transport of persistent organic pollutants to the Arctic, Nat. Commun., 3, 862, doi:10.1038/ncomms1858, 2012.

Galbán-Malagón, C. J., Del Vento, S., Cabrerizo, A., and Dachs, J.: Factors affecting the atmospheric occurrence and deposition of polychlorinated biphenyls in the Southern Ocean, Atmos. Chem. Phys., 13, 12029-12041, doi:10.5194/acp-13-12029-2013, 2013.

García-Flor, N., Guitart, C., Ábalos, M., Dachs, J., Bayona, J. M., and Albaigés, J.: Enrichment of organochlorine contaminants in the sea surface microlayer: An organic carbon-driven process, Mar. Chem., 96, 331-345, 2005.

García-Flor, N., Dachs, J., Bayona, J. M., and Albaigés J.: Surface waters are a source of polychlorinated biphenyls to the coastal atmosphere of the North-Western Mediterranean Sea, Chemosphere, 75, 1144-1152, 2009.

Garrison, V. H., Majewski, M. S., Foreman, W. T., Genualdi, S. A., Mohammed, A., and Massey Simonich, S. L.: Persistent organic contaminants in Saharan dust air masses in West Africa, Cape Verde and the eastern Caribbean, Sci. Total Environ., 468-469, 530-543, 2013

Gioia, R., Nizzetto, L., Lohmann, R., Dachs, J., Temme, C., and Jones, K. C.: Polychlorinated biphenyls (PCBs) in air and seawa- ter of the Atlantic Ocean: sources, trends and processes, Environ. Sci. Technol., 42, 1416-1422, 2008.

Goss, K. U. and Schwarzenbach, R. P.: Gas/solid and gas/liquid partitioning of organic compounds: Critical evaluation of the interpretation of equilibrium constants, Environ. Sci. Technol., 32, 2025-2032, 1998.

Gouin, T., Thomas, G. O., Cousins, I., Barber, J., Mackay, D., and Jones, K. C.: Air-surface exchange of polybrominated diphenyl ethers and polychlorinated biphenyls, Environ. Sci. Technol., 36, 1426-1434, 2002.

Harner, T. and Bidleman, T. F.: Measurement of octanol-air partition coefficients for polychlorinated biphenyls, J. Chem. Eng. Data, 41, 895-899, 1996.

Harner, T. and Bidleman, T. F. Octanol-air partition coefficient for describing particle/gas partitioning of aromatic compounds in urban air. Environ. Sci. Technol., 32, 1494-1502, 1998.

Hung, H., Lee, S. C., Wania, F., Blancharda, P., and Briceet, K.: Measuring and simulating atmospheric concentration trends of polychlorinated biphenyls in the Northern Hemisphere, Atmos. Environ., 39, 6502-6512, 2005.

Iwata, H., Tanabe, S., Sakal, N., and Tatsukawa, R.: Distribution of persistent organochlorines in the oceanic air and surface seawater and the role of ocean on their global transport and fate, Environ. Sci. Technol., 27, 1080-1098, 1993.

Jaward, F., Barber, J., Booij, K., Dachs, J., Lohmann, R., and Jones, K. C.: Evidence for dynamic air-water coupling and cycling of persistent organic pollutants over the open Atlantic Ocean, Environ. Sci. Technol., 38, 2617-2625, 2004.

Jones, K. C. and De Voogt, P.: Persistent organic pollutants (POPs): state of the science, Environ. Pollut., 100, 209-221, 1999.

Jurado, E. and Dachs, J.: Seasonality in the "grasshopping" and atmospheric residence times of persistent organic pollutants over the oceans, Geophys. Res. Lett., 35, L17805, doi:10.1029/2008GL034698, 2008.

Jurado, E., Jaward, F. M., Lohmann, R., Jones, K. C., Simó, R., and Dachs, J.: Atmospheric dry deposition of persistent organic pollutants to the Atlantic and inferences for the global oceans, Environ. Sci. Technol., 38, 5505-5513, 2004.

Jurado, E., Jaward, F., Lohmann, R., Jones, K.C., Simó, R., and Dachs, J.: Wet deposition of persistent organic pollutants to the global oceans, Environ. Sci. Technol., 39, 2426-2435, 2005.

Kömp, P. and McLachlan, M. S.: Octanol/air partitioning of polychlorinated biphenyls, Environ. Toxicol. Chem., 16, 2433-2437, doi:10.1002/etc.5620161201, 1997.

Li, N., Wania, F., Lei, Y. D., and Daly, G. L.: A comprehensive and critical compilation, evaluation, and selection of physicalchemical property data for selected polychlorinated biphenyls, J. Phys. Chem. Ref. Data, 32, 1545-1590, doi:10.1063/1.1562632, 2003.

Lohmann, R., Gioia, R., Jones, K. C., Nizzetto, L., Temme, C., Xie, Z., Schulz-Bull, D., Hand, I., Morgan, E., and Jantunen, L.: Organochlorine pesticides and PAHs in the surface water and atmosphere of the North Atlantic and Arctic Ocean, Environ. Sci. Technol., 43, 5633-5639, 2009.

Mandalakis, M. and Stephanou, E. G.: Study of atmospheric PCB concentrations over the eastern Mediterranean Sea, J. Geophys. Res., 107, 4716, doi:10.1029/2001JD001566, 2002. 
Mandalakis, M. and Stephanou, E. G.: Atmospheric concentration characteristics and gas-particle partitioning of PCBs in a rural area of Eastern Germany, Environ. Pollut., 147, 211-221, 2007.

Mandalakis, M., Berresheim, H., and Stephanou, E. G.: Direct evidence for destruction of polychlorobiphenyls by $\mathrm{OH}$ radicals in the subtropical troposphere, Environ. Sci. Technol., 37, 542-547, 2003.

Mandalakis, M., Apostolaki, M., Stephanou, E. G., and Stavrakakis S.: Mass budget and dynamics of polychlorinated biphenyls in the eastern Mediterranean Sea, Global Biogeochem. Cy., 19, GB3018, doi:10.1029/2004GB002403, 2005.

Nizzetto, L., Macleod, M., Borgå, K., Cabrerizo, A., Dachs, J., Di Guardo, A., Ghirardello, D., Hansen, K. M., Jarvis, A., Lindroth, A., Ludwig, B., Monteith, D., Perlinger, J. A., Scheringer, M., Schwendenmann, L., Semple, K. T., Wick, L. Y., Zhang, G., and Jones, K. C.: Past, present, and future controls on levels of persistent organic pollutants in the global environment, Environ. Sci. Technol., 44, 6526-6531, 2010a.

Nizzetto L., Lohmann R., Gioia R., Dachs J., and Jones, K. C.: atlantic ocean surface waters buffer declining atmospheric concentrations of persistent organic pollutants, Environ. Sci. Technol., 44, 6978-6984, 2010b.

Nizzetto, L., Gioia, R., Li, J., Borgå, K., Pomati, F., Bettinetti, R., Dachs, J., and Jones, K. C.: Biological pump control of the fate and distribution of hydrophobic organic pollutants in water and plankton, Environ. Sci. Technol., 46, 3204-3211, 2012.

Querol, X., Alastuey, A., Pey, J., Cusack, M., Pérez, N., Mihalopoulos, N., Theodosi, C., Gerasopoulos, E., Kubilay, N., and Koçak, M.: Variability in regional background aerosols within the Mediterranean, Atmos. Chem. Phys., 9, 4575-4591, doi:10.5194/acp-9-4575-2009, 2009.

Radonić, J., Miloradov, M. V., Sekulić, M. T., Kiursk, J., Djogo, M., and Milovanović, D. The octanol-air partition coefficient, $K_{\mathrm{OA}}$, as a predictor of gas-particle partitioning of polycyclic aromatic hydrocarbons and polychlorinated biphenyls at industrial and urban sites, J. Serb. Chem. Soc., 76, 447-458, 2011.

Regaudie-de-Gioux, A., Vaquer-Sunyer, R., and Duarte, C. M.: Patterns in planktonic metabolism in the Mediterranean Sea, Biogeosciences, 6, 3081-3089, doi:10.5194/bg-6-3081-2009, 2009.

Schwarzenbach, R., Gschwend, P. M., and Imboden D. M.. Environmental Organic Chemistry, Willey-Interscience, New York, p. $163,2003$.
Shen, L. and Wania, F.: Compilation, Evaluation, and Selection of Physical-Chemical Property Data for Organochlorine Pesticides, J. Chem. Eng. Data., 50, 742-768, 2005.

Shoeib, M. and Harner, T.: Using measured octanol-air partition coefficients $\left(K_{\mathrm{OA}}\right)$ to explain environmental partitioning of organochlorine pesticides, Environ. Toxicol. Chem., 21, 984990, 2002.

Simó, R. and Dachs, J.: Global ocean emission of dimethylsulfide predicted from biogeophysical data, Global Biogeochem. Cy., 16, 1078, doi:10.1029/2001GB001829, 2002.

Spivakovsky, C. M., Logan, J.A., Montzka, S. A., Balkanski, Y. J., Foreman-Fowler, M., Jones, D. B. A., Horowitz, L. W., Fusco, A. C., Brenninkmeijer, C. A. M., Prather, M. J., Wofsy, S. C., and McElroy M. B.: Three-dimensional climatological distribution of tropospheric OH: Update and evaluation, J. Geophys. Res., 105, 8931-8980, doi:10.1029/1999JD901006, 2000.

Tolosa, I., Readman, J. W., Fowler, S. W., Villeneuve, J. P., Dachs, J., Bayona, J. M., and Albaiges, J.: PCBs in the western Mediterranean. Temporal trends and mass balance assessment, Deep-Sea Res. Pt. II, 44, 907-928, 1997.

Turley, C. M.: The changing Mediterranean Sea - a sensitive ecosystem?, Prog. Oceanogr., 44, 387-400, 1999.

Turley, C. M., Bianchi, M., Christaki, U., Conan, P., Harris, J. R. W., Psarra, S., Ruddy, G., Stutt, E. D., Tselepides, A., and Van Wambeke, F.: Relationship between primary producers and bacteria in an oligotrophic sea-the Mediterranean and biogeochemical implications, Mar. Ecol.-Prog. Ser., 193, 11-18, 2000.

United Nations Environment Programme (UNEP): Mediterranean regional report, Regionally Based Assessment of Persistent Toxic Substances, available at: www.chem.unep.ch/Pts/ regreports/Mediterranean.pdf (last access: February 2014), 2002.

United Nations: Stockholm Convention on Persistent Organic Pollutants (POPs), available at: http://chm.pops.int, last access: 1 February 2014.

Wania, F. and Daly, G. L.: Estimating the contribution of degradation in air and deposition to the deep sea to the global loss of PCBs, Atmos. Environ., 36, 5581-5593, 2002.

Wania, F., Erikhaugen, J., Lei, Y., and Mackay, D.: Temperature dependence of atmospheric concentrations of semivolatile organic compounds, Environ. Sci. Technol., 32, 1013-1021, 1998.

Zhang, L. and Lohmann, R.: Cycling of PCBs and HCB in the surface ocean-lower atmosphere of the open pacific, Environ. Sci. Technol., 44, 3832-3838, 2010. 